\title{
Análise do desenvolvimento territorial: a contribuição da experiência italiana
}

\author{
Analysis of territorial development: the contribution of italian experience
}

\section{Analyse du developpement territorial: la contribution de l'expérience italienne}

\section{Análisis del desarrollo territorial: la contribución de la experiencia italiana}

\author{
Elaine Carvalho de Lima ${ }^{1}$ \\ Calisto Rocha de Oliveira Neto ${ }^{2}$
}

Recebido em 25/12/2017; revisado e aprovado em 14/06/2018; aceito em 20/07/2018

DOI: http://dx.doi.org/10.20435/inter.v0i0.1796

\begin{abstract}
Resumo: O objetivo do presente artigo é realizar uma revisão da literatura sobre os distritos industriais e sua contribuição para a discussão do desenvolvimento territorial. Constata-se que a abordagem territorial tem ganhado importância na definição de políticas de desenvolvimento por se estabelecer no lócus de execução da política, o que permite o desenvolvimento de cooperação e complementaridade.
\end{abstract}

Palavras-chave: terceira Itália; desenvolvimento territorial; capitalismo.

Abstract: The purpose of this article is to review the literature on industrial districts and their contribution to the discussion of territorial development. It appears that the territorial approach has gained importance in the definition of development policies by establishing the policy execution locus, which allows the development of cooperation and complementarity.

Keywords: third Italy; territorial development; capitalism.

Résumé: Le but de cet article est de passer en revue la littérature sur les districts industriels et leur contribution à la discussion sur le développement territorial. On peut voir que l'approche territoriale a pris de l'importance dans la définition des politiques de développement en s'installant au centre de la mise en œuvre des politiques, ce qui permet le développement de la coopération et de la complémentarité.

Mots-clés: troisième Italie; développement territorial; capitalisme.

Resumen: El objetivo del presente artículo es realizar una revisión de la literatura sobre los distritos industriales y su contribución a la discusión del desarrollo territorial. Se constata que el enfoque territorial ha adquirido importancia en la definición de políticas de desarrollo por establecerse en el locus de ejecución de la política, lo que permite el desarrollo de cooperación y complementariedad.

Palabras claves: tercera Italia; desarrollo territorial; capitalismo.

\section{INTRODUÇÃO}

As transformações advindas pela globalização têm direcionado as atividades econômicas a novas dinâmicas que requerem adaptação aos novos estágios da competitividade mundial. No âmbito econômico, a globalização vai ser marcada pela desnacionalização financeira e intensa mobilidade do capital, além da vantagem da eliminação de fronteiras espaciais e temporais com as tecnologias de informação e comunicação. No quadro político, a maior perda diz respeito à autonomia do Estado nacional, ao centralizar as decisões em um número minoritário de grandes empresas e instituições com poder econômico global. Assim, os atores mais relevantes na globalização passam a ser os conglomerados e as empresas transnacionais que possuem o poderio tecnológico, produtivo, comercial e financeiro.

Como salientado por Chesnais (1996), os avanços das tecnologias de informação e comunicação emergiram como um facilitador da globalização do capital, assim: "[...] tais avanços

\footnotetext{
${ }^{1}$ Universidade Federal de Uberlândia (UFU), Uberlândia, Minas Gerais, Brasil.

${ }^{2}$ Universidade Federal Rural do Semiárido (UFERSA), Mossoró, Rio Grande do Norte, Brasil.
} 
dos meios de comunicação, monitoramento e controle, permitem a expansão, praticamente ilimitada da propensão representada pela capacidade de investir e desinvestir, empregar e desempregar, contratar e destratar" (MARTINS, 1996, p. 2).

Diante disso, a abordagem territorial tem ganhado espaço na definição de políticas de desenvolvimento por se estabelecer no lócus de execução da política, o que permite o desenvolvimento de cooperação e complementaridade. Porter (1999) e Benko (2001) ressaltam que a dimensão territorial possui um componente atuante da vantagem competitiva, uma vez que as atividades mais competitivas de um determinado espaço se concentram em regiões em forma de clusters (aglomerações). Nesse sentido, o objetivo do presente artigo é realizar uma revisão da literatura sobre os distritos industriais italianos, a partir da experiência da Terceira Itália, e sua contribuição para a discussão do desenvolvimento territorial. Para isso foram analisados artigos científicos, livros teses e dissertações que abordaram tal temática.

Nessa perspectiva, a análise do presente artigo está direcionada sobre as estratégias endógenas de desenvolvimento, as quais são coordenadas por atores locais e fundamentadas em fatores de competitividade. Dessa forma, a dinâmica dos distritos industriais e suas transformações das estruturas de governança trazem elementos indispensáveis para se repensar o desenvolvimento nas diferentes localidades.

O artigo está dividido em mais quatro seções, além dessa parte introdutória. A seguir, faz-se uma revisão de literatura sobre a crise do fordismo e a implantação de um padrão flexível. Na seção três, realiza-se a exposição do debate sobre as teorias de localização e de desenvolvimento econômico. Na seção quatro, discute-se sobre o caso dos distritos italianos e, por fim, as considerações finais.

\section{CRISE DO FORDISMO E O NOVO PARADIGMA DA PRODUÇÃO FLEXÍVEL}

Durante muito tempo, considerou-se o liberalismo econômico da segunda metade do século XIX e início do século XX como sinônimo de prosperidade socioeconômica e, consequentemente, desenvolvimento do capitalismo. Contudo, com a crise econômica de 1929, emergiu uma nova vertente de pensamento econômico, que passou a ser hegemônica do modo de produção capitalista, a teoria keynesiana.

O Estado de Bem Estar Social estava fundamentado nessa teoria, que tinha, nos países europeus e nos Estados Unidos, o princípio norteador de geração do pleno emprego e diminuição das desigualdades sociais entre os cidadãos. Ademais, propõe a visão de que os governos possuem a responsabilidade de garantir um padrão de vida digno para os cidadãos.

Nesse sentido, as políticas de Estado, sustentadas na teoria keynesiana, possibilitaram a chamada "Era Dourada do Capitalismo", que atravessou a década de 1940 à década de 1970 e foi marcado por elevado crescimento econômico em diversos países do mundo.

Todavia, segundo Benko (2002), em meados da década de 1970, o modelo fordista de produção capitalista, símbolo da acumulação de capital dos trinta anos de crescimento econômico, entra num processo de esgotamento na geração de elevadas taxas de lucro e por uma reestruturação da (re)produção de capital. Assim, o modelo fordista, direcionado para uma relação de produção e consumo em massa, entra em crise.

Dessa forma, o declínio do paradigma fordista de produção em massa é uma cisão na forma como se pensava a geração de riqueza e consumo em massa. Assim, com a fragilização 
estrutural daquele paradigma, abria-se espaço para novas formas de acumulação de capital, pouco rígida e mais flexível e eficiente, estruturada no desenvolvimento da tecnologia da informação e da produção de conhecimento. Estas são consideradas estratégias capitalistas inovadoras de racionalização da produção as quais buscam reestruturar o modelo capitalista de acumulação através de um novo modelo de crescimento e desenvolvimento econômico.

Nesses termos, a flexibilização da produção surge como um novo modelo de acumulação capitalista, que se apresenta como solução para superar a crise econômica da década de 1970 causada pela crise de oferta de petróleo e estagflação.

Nesse sentido, a aceleração da informatização veio a fortalecer os investimentos sob a forma de capital financeiro e o abandono por partes dos Estados das políticas intervencionistas orientadas à la Keynes. Outrossim, num cenário de intensa globalização, o Estado Nacional transfere suas responsabilidades para o mercado, os benefícios sociais para a iniciativa privada e a soberania nacional para a ordem dominante mundial com consequências visíveis na desregulamentação e destruição dos direitos sociais (ABREU, 2000). Como mostrado por Laurell (1992, p. 163):

O Estado só deve intervir com o intuito de garantir um mínimo para aliviar a pobreza e produzir serviços que os privados não podem ou não querem produzir, além daqueles que são, a rigor, de apropriação coletiva. Propõem uma política de beneficência pública ou assistencialista com um forte grau de imposição governamental sobre que programas instrumentar e quem instruir, para evitar que se gerem "direitos". Além disso, para se ter acesso aos benefícios dos programas públicos, deve-se comprovar a condição de indigência. Rechaça-se o conceito dos direitos sociais e a obrigação da sociedade de garanti-los através da ação estatal. Portanto, o neoliberalismo opõe-se radicalmente à universalidade, igualdade e gratuidade dos serviços sociais.

Notadamente, a globalização econômica, através das políticas neoliberais, é a resposta do capital à crise instalada nos 1970, que buscava retomar o processo de acumulação de capital através da alteração do modo de produção, que tinha na flexibilização da produção, bem como nas mudanças no mercado de trabalho, seus pilares principais.

Tal flexibilização produtiva implementou novas formas de organização da produção, principalmente pela eliminação da produção em massa e orientando a demanda de mercado e em produtos diferenciados. Inclusive, por não haver produção em massa e, consequentemente, elevados estoques, o toyotismo, como também é conhecido, possibilita reduzir custos devido à produção enxuta, informatizada e de elevada comunicação, que possibilitou aumentar as taxas de lucro.

Todo esse processo evidenciou que a cadeia produtiva fordista peca por "rigidez"; Benko (2002) destaca que a luta contra essa "rigidez", perpassa pela passagem para um novo regime de acumulação que "[...] acompanhasse as mudanças fundamentais multiformes nos modos de produção e de consumo, nas transações e nos mecanismos institucionais de regulação das relações sociais. Eles induzem uma reestruturação espacial da sociedade inteira [...]" (BENKO, 2002, p. 29).

A partir dessa análise, Piore e Sabel (1984) chamam atenção para o fato de que a especialização flexível passou a ser uma resposta para a superação da crise da produção em massa que era típica da produção fordista. Nesse sentido, esse novo paradigma emerge em decorrência de novas demandas do mercado por uma produção de qualidade e diferenciada. 
Dentro dessa perspectiva de decadência da produção fordista e ascensão de um novo modelo de acumulação enxuto e flexível, surgem novas formas de enxergar a dimensão espacial e territorial como plataforma de criação e implementação de programas de desenvolvimento no plano local e regional, com maior autonomia a partir de descentralizações das decisões, uma perspectiva sobre a qual a próxima seção debaterá com maiores detalhes.

\section{TERRITÓRIO E DESENVOLVIMENTO ECONÔMICO}

Benko (2002) evidencia que, com as mudanças ocorridas com o advento da internacionalização econômica e mudança do papel do Estado, sucedeu-se uma alteração nas escalas locais e regionais dos territórios. O autor destaca quatro mudanças dessa evolução: aceleração da mobilidade de capital; acirramento da concorrência entre espaços nacionais e empresas transnacionais; crescente transnacionalização das economias e produção; e um ambiente econômico cada vez mais transnacional.

Salienta-se que os estudos sobre a organização territorial das atividades não são recentes, pois envolvem problemas recorrentes como a influência das vantagens geográficas sobre o modo de crescimento das regiões, das instituições, da estrutura econômica etc. Observa-se que a localização das atividades tem uma função importante na teoria econômica, e a existência de desigualdades entre os mais diversos espaços é algo que tem gerado muitos debates e estudos na literatura (BENKO, 1999).

Desse modo, a economia espacial deve ser compreendida como resultado da interação de forças aglomerativas e desaglomerativas (OTTAVIANO; THISSE, 2004). Isto é, concentrar ou desconcentrar as atividades econômicas em um ponto geográfico, a partir das vantagens existentes em determinada região.

De modo geral, as economias de aglomeração podem ser classificadas em:

a) Economias de escala: relacionam-se as reduções dos custos unitários de uma empresa, decorrente da expansão da escala de produção;

b) Economias de localização: vantagens em estar próximo de outras firmas que podem possibilitar redução de custos;

c) Economias de urbanização: decorre do aumento do nível econômico na região em que a empresa está localizada.

Nos primeiros estudos da economia espacial, urbana ou regional, destacam-se os trabalhos da Escola de lena (LOSH, 1940; CHRISTALLER, 1933). A partir de uma análise clássica da localização das atividades econômicas, a preocupação desses estudiosos fundamentava-se nas decisões de minimização de custos e maximização dos lucros.

Christaller (1933) estudou o processo de urbanização, bem como a maior importância adquirida pelas cidades no ordenamento espacial. O autor partiu da hipótese de que os lugares econômicos seguem a racionalidade hierárquica conforme uma rede de interdependência que tenderia à centralização (BENKO, 2002). Assim, as áreas constituídas por aglomerações seriam como o lugar central, este caracterizado pela centralidade de bens e serviços.

O nível de organização da população determinaria a quantidade de bens consumidos, pois o consumo de um bem estaria condicionado à distância que o indivíduo percorre para obtê-lo. Dessa maneira, há a introdução do conceito de distância econômica em substituição de distância geográfica, pois deve-se levar em consideração os custos incorridos com frete, armazenamento, seguro e transporte, ou seja, o custo de acesso (CHRISTALLER, 1933; BREITBACH, 1988). 
Breitbach (1988) salienta que a abordagem teórica adotada por Christaller (1933) contribui para o entendimento do fenômeno regional, visto que a ideia de organização do espaço pautada pela existência de uma dependência entre o centro urbano e uma região complementar levanos a pensar em diversos fatores que influenciam na distribuição territorial da população e das atividades econômicas no espaço.

Benko (2002) chama atenção para o caráter estruturalista da teoria dos Lugares Centrais, em que a estrutura é mais importante do que a descrição do fenômeno que a compõe. Além disso, o autor ao realizar a crítica sobre tal teoria afirma que:

Certas cidades se saem melhor que outras porque elas o "merecem", porque a vida econômica (ou cultural) é aí mais ativa, porque os cidadãos nelas adotam atitude mais cooperativa ou mais bem concertada. A partir daí, a hierarquia espacial passa a ser resultado e não causa: todas as cidades poderiam ser igualmente prósperas se agissem da mesma forma. (BENKO, 2002, p. 53).

Uma das principais críticas à teoria mencionada diz respeito ao caráter homogêneo. "O problema é que as regiões, e ainda menos as nações, não são homogêneas umas em relação às outras" (BENKO, 2002, p. 53).

A partir dos anos 1960, os estudos do desenvolvimento desigual entre regiões ou nações passaram a ocupar um espaço importante nas discussões, destacando-se o esquema de ClarkRostow-Vernon. Para Clark (1957), a região dita desenvolvida passou pelas etapas pré-industrial (primária), industrial (secundária) e pós-industrial (terciária ou quaternária). Contudo, segundo a teoria das etapas de desenvolvimento de Rostow (1978), tal autor sustenta que nem todas as regiões "atravessariam" as etapas da mesma forma, ocorrendo o subdesenvolvimento de uns em relação a outros na história do capitalismo. E, por fim, Vernon (1966) desenvolveu a teoria do ciclo do produto, segundo a qual "[...] os novos produtos inventados nas zonas mais desenvolvidas banalizariam e sua produção deslocar-se-ia para as regiões menos desenvolvidas".

As teorias de desenvolvimento desigual enfatizam as disparidades de nível e ritmo de desenvolvimento entre as diferentes regiões. Por seu turno, Myrdal (1968) trouxe avanços em sua investigação a partir de algumas constatações, tais quais: existência de um pequeno número de países prósperos e um número grande de países extremamente pobres; os países prósperos são caracterizados por um processo de desenvolvimento econômico contínuo, em detrimento do segundo grupo; as desigualdades entre os dois grupos têm se elevado ao longo dos anos.

Tal dualismo retratado por Myrdal (1968) é visto como um entrave na organização da estrutura econômica de um país. O autor difundiu a "Teoria da Causação Cumulativa" como forma de evidenciar o hiato crescente entre os diferentes espaços, pois, ao ocasionar o crescimento de uma área, acentuariam-se os efeitos regressivos nas demais áreas, tal relação seria um dos efeitos dos movimentos do capital. Sendo assim, isto agravaria ainda mais as disparidades regionais, pois o processo cumulativo poderia ocorrer para cima (efeitos propulsores) nas regiões mais desenvolvidas, ou para baixo (efeitos regressivos) nas regiões menos desenvolvidas.

Em linhas gerais, para Myrdal (1968), nos países mais pobres os efeitos propulsores são fracos e não acarretam mudanças nas desigualdades existentes nesses países, por conseguinte, os efeitos propulsores tornam-se mais fortes quanto maior for o nível de desenvolvimento, tendo em vista as condições sociais e econômicas.

Hirschman (1958) chama atenção para os efeitos de transbordamento e polarização do crescimento que ocorrem de modo mais intenso nas relações econômicas entre regiões nacionais 
do que internacionais. Tal processo pode ser justificado pela interação mais forte existente entre as regiões subnacionais. $O$ autor também enfatiza a importância de se estudar as especificidades de cada local, visto que as economias regionais não podem ser consideradas como versões simplificadas das economias nacionais.

Ainda segundo o autor, o investimento induzido iria promover o desenvolvimento regional, via estímulo dos setores chave que complementassem a matriz produtiva local. O crescimento econômico é tido como um processo desequilibrado, no qual alguns setores se sobressaem em relação a outros, surgem assim, gargalos produtivos que devem ser analisados pelo mercado e governo como sinalização para o investimento.

Em meados da década de 1980, uma série de trabalhos ganhou notoriedade através do crescimento de regiões industriais em decorrência da dinâmica interna. Tal análise conduziu a uma nova teorização do desenvolvimento regional, que ficou conhecida como teoria do crescimento endógeno. Dentre os estudos, sobressaem os de Bagnasco, Trigilia e Brusco sobre a Terceira Itália. Salienta-se que Marshall (1890) foi um dos pioneiros nos estudos sobre a existência das aglomerações produtivas e as externalidades locais geradas em prol do crescimento da indústria, em que a localização das empresas era vista como ambiente gerador de vantagens competitivas.

Nesse sentido, muitos teóricos mostraram que o modelo de desenvolvimento deveria incluir: regime de acumulação, paradigma tecnológico e modo de regulação das relações trabalhistas, assim:

[...] a velha forma fordista não está morta: a grande empresa, com sua rede hierarquizada de estabelecimentos, sucursais e empresas subcontratadas, repartidas pelo espaço pela mão bem visível da planificação empresarial. Em seguida os distritos à italiana são casos particulares, extremamente dependentes de uma macroeconomia mundial que lhes escapa, sujeitos a laços de dependência que ignoram. As qualidades que se Ihes atribuem ocultam os custos sociais: trabalho superexplorado das mulheres etc. A qualificação não é de modo nenhum o traço característico deste novo modelo. [...] esse modelo pode assumir diferentes formas, e a velha hierarquia (típica das multinacionais fordistas) pode operar um regresso em força sob a máscara mercantil das relações de subcontrataçãoo. (BENKO; LIPIETZ, 1994, p. 249).

Por fim, observou-se que o novo paradigma tecnológico da especialização flexível trouxe novos horizontes para a organização produtiva, tecnológica e de gestão das empresas, em que a hierarquia das cidades seria decorrente das estratégias internas desses distritos.

\section{OS DISTRITOS INDUSTRIAIS: O CASO DA TERCEIRA ITÁLIA}

A literatura econômica tem evidenciado que as aglomerações de empresas, tanto em países desenvolvidos quanto em desenvolvimento, geram vantagens competitivas que as empresas dispersas territorialmente não conseguiriam (ERBER, 2008). Além disto, tais aglomerações possibilitam melhorias no desempenho doméstico e na atuação em mercados mais distantes (SCHMITZ, 1992). De forma geral, Becattini (1994, p. 20) conceitua o distrito industrial como uma "entidade socioterritorial caracterizada pela presença ativa de uma comunidade de pessoas e de uma população de empresas num determinado espaço geográfico e histórico".

Antes de investigar com mais detalhes as aglomerações industriais, cabe destacar que a temática não é recente, tendo como um dos trabalhos pioneiros o do economista Alfred Marshall (1842-1924) com a obra "Principles of economics" publicada em 1890. O autor analisou as 
aglomerações nos distritos industriais ingleses, que diz respeito aos ganhos de escala (economias externas) decorrentes dessas aglomerações.

Um ponto importante a destacar é que as economias externas marshallianas possuem uma relevância na explicação de tais aglomerações, entretanto não garantem uma explicação completa como salientam Schmitz e Nadvi (1999), visto que as economias externas locais não são decorrentes apenas da produção (spillovers), mas também da distribuição, serviços especializados, entre outros fatores que vão além do espaços aglomerativos (SCHMITZ; NADVI, 1999).

A experiência de aglomeração e clusters no sucesso do desempenho das pequenas empresas foram objetos de vários estudos (SCHMITZ, 1992; SCHMITZ; NADVI, 1999). Além do mais, a partir da experiência europeia, especialmente os casos italianos tornaram-se referência para estudos sobre agrupamento de economias em desenvolvimento, refletido no aumento da literatura e nos efeitos benéficos, como a eficiência coletiva promovida nesse ambiente (SCHMITZ; NADVI, 1999). Nesse sentido, ao se referir ao caso italiano, Bagnasco (1999, p. 39) defende que "[...] a formação do capital, as capacidades de gestão, as qualificações técnicas, a confiança recíproca e um bom clima social são recursos decisivos, qualquer que seja o tipo de desenvolvimento".

Schmitz e Musyck (1993) destacam que as décadas de 1970 e 1980 foram de grande notoriedade para os distritos industriais europeus, apesar de serem constituídos por pequenas e médias empresas. Tais distritos conseguiram competitividade internacional com elevados números de emprego. Schmitz (1992) analisou os distritos industriais italianos, o caso da Terceira Itália, evidenciando que o ponto forte se encontra na aglomeração e na competição cooperativa.

Feitosa (2009) aponta dois fatores que caracterizam esse período no território italiano. 0 primeiro diz respeito aos avanços econômicos marcados por uma elevada taxa de crescimento do PIB e, quando comparado ao restante do continente europeu, a Itália alcançou o quarto PIB na Europa. O segundo elemento destacado por Feitosa (2009) está relacionado ao período anterior que era caracterizado pelas disparidades regionais que, entre outros fatores, resultou em um dualismo estrutural entre o norte e sul italiano. O norte italiano era predominantemente industrializado com a existência de grandes empresas denominado por Primeira Itália, enquanto que no sul predominava a existência de pequenas firmas caracterizadas por produzir especialmente para o mercado local e com pouco progresso, esta ficou conhecida como Segunda Itália.

Nesse contexto, surgiu uma "Terceira Itália", região entre o Norte e Sul italiano, onde se localizam Milão, Turim, Bolonha, Florença, Ancona, Veneza, Modena e Gênova. Tal região era constituída por micro, pequenas e médias empresas, e estas promoveram o crescimento e a formação dos distritos industriais, gerando um ambiente propício para estratégias de cooperação, inovação e relações de confiança. Além disso, Becattini (1999) ressalta a importância da comunidade local caracterizada por um sistema homogêneo de valores e visões, a partir da existência de instituições que transmitiam tais relações ao longo das várias gerações.

Nesse processo de expansão da "Terceira Itália", é importante destacar o papel intenso da cooperação entre as empresas com a utilização de métodos flexíveis de produção e da parceria com as universidades locais na geração de novos conhecimentos. Além do mais, a reordenação da produção atendia aos novos anseios do processo de globalização mundial, pois abarcava a superação do modo de produção em massa e da limitação dos mercados nacionais (DUAIBS, 2016; FEITOSA, 2009).

Duaibs (2016) destaca que os distritos englobavam os setores tradicionais, tais como têxteis e confecções, alimentos, móveis, couro e calçados, mas também setores ligados à química, 
eletrônica, metal mecânica. Em geral, cada distrito se especializava em determinadas áreas e possuíam uma relação com o mercado final.

Nesse contexto, observa-se que, a partir da experiência relatada, as pequenas empresas têm desempenhado um papel importante no desenvolvimento econômico, porém a viabilidade econômica dessas empresas permanece como uma questão central nas discussões. Alguns autores defendem a necessidade de aprofundar o debate sobre essa questão ao mostrar que as atividades da pequena empresa tornam-se vantajosas se forem economicamente viáveis. Nesse sentido, Schmitz (1992, p. 64, tradução nossa) enfatiza ser viável: "[...] a capacidade de crescer ou, pelo menos, de sobreviver, tendo em mente que a permanência ainda é suficiente para a sobrevivência".

Nesse contexto, o autor destaca uma certa insuficiência sobre as conclusões da viabilidade econômica. Em síntese, os resultados podem abarcar dois pontos relevantes: o primeiro diz respeito ao grau de importância das pequenas empresas nos países desenvolvidos e menos desenvolvidos, divergindo dos enfoques iniciais de que a pequena empresa diminuiria com o processo de crescimento econômico. No segundo ponto, observa-se que as generalizações sobre a viabilidade de tais empresas não são, em geral, sustentáveis (SCHMITZ, 1992).

Observa-se uma atenção especial ao espaço "regional" como o correlato ao "global" em virtude do crescimento dos clusters industriais regionais e locais globalmente competitivos; especialmente, quando relacionados às tecnologias de informação e comunicação, que possuem sólidos vínculos verticais e horizontais entre as empresas. Schmitz (1992) chama atenção para o fato de que o agrupamento de empresas facilita os ganhos de eficiência em que dificilmente empresas individuais lograriam êxito. Assim, o conceito de eficiência coletiva é introduzido para apreender esses ganhos.

Uma série de fatores contribui para entendimento do que venha a ser eficiência coletiva. Diante disso, Schmitz (1992) explica que a concentração geográfica e setorial não garante a geração de benefícios mútuos entre as empresas, mas sim os desdobramentos decorrentes, entre outros fatores, da divisão do trabalho e especialização; da capacidade de fornecer os produtos/serviços com grande velocidade e prazos curtos; agentes que comercializem a distantes mercados nacionais e internacionais; trabalhadores com capacitações setoriais específicas; fornecedores que ofereçam matérias-primas, máquinas novas e usadas, além de peças de reposição.

Assim, a eficiência coletiva decorre de um processo interno em que algumas empresas crescem e outras diminuem. Ademais, a existência de eficiência coletiva não se opõe à existência de concorrência e conflitos entre as empresas das aglomerações, ao contrário, encoraja a concorrência e colabora com o enfrentamento de problemas comuns, por meio de associações ou governo local.

Entre os exemplos europeus dos clusters considerados por Schmitz e Musyck (1993), verificou-se que as características gerais de medidas pró-ativas no investimento em recursos humanos e de capacitação envolveram o setor privado em nível local, na tentativa de conseguir uma maior sintonia com as necessidades das empresas locais. Ademais, os distritos industriais surgem de forma espontânea em virtude de circunstâncias históricas, políticas, econômicas e sociais, sendo dificilmente consequência de ações planejadas ou políticas industriais. Os autores também argumentaram que o sucesso dos distritos industriais na Europa se baseia num sistema que socializa o risco em uma ampla gama de instituições públicas e privadas. 
Schmitz e Nadvi (1999) destacam dois pré-requisitos para explorar o potencial de clusters. O primeiro diz respeito à existência de rede de comércio, e o outro seria a existência de sanções eficazes e de confiança. Para os autores, qualquer lacuna nesses pré-requisitos pode afetar a mobilização de recursos financeiros e humanos nos clusters.

Ademais, tais autores mostram que os clusters industriais têm provocado grandes interesses aos policy makers, especialmente quanto ao potencial de geração de emprego e o potencial das pequenas e médias empresas em alcançar mercados em nível global. Os autores tomaram como base o trabalho de Humphey e Schmitz (1996) e defendem que, para serem efetivas, as intervenções devem ser: "customer-oriented", permitir que as empresas tenham um maior conhecimento sobre as necessidades dos seus clientes, o que pode resultar em aspectos centrais da competitividade; "collective", decorre do incentivo à cooperação e aprendizado mútuo entre as empresas; "cumulative", gera uma capacidade contínua de melhorias.

Dessa forma, pode-se constatar uma elevada importância das aglomerações e seus desdobramentos no aumento da competitividade das empresas, do processo de aprendizado inovativo, na geração de emprego e renda; inclusive, na articulação com as micro e pequenas empresas que geram um maior suporte para essa categoria de empresas e ajudam a ultrapassar possíveis barreiras de crescimento, especialmente nos países em desenvolvimento (ERBER, 2008). Diante disso, a abordagem territorial tem ganhado espaço na definição de políticas de desenvolvimento, por se estabelecer no lócus de execução da política, o que permite o desenvolvimento de cooperação e complementaridade.

Em suma, o progresso na Terceira Itália tornou-se uma experiência exitosa do papel da dinâmica das atividades econômicas locais a geração de externalidades positivas para os que ali estão localizados. De fato, a herança local foi muito importante para a região que incluía, entre outros fatores, tradição cívica, estrutura de governança local e regional, acesso às universidades, sistema urbano constituído e capital social desenvolvido. Dessa forma, o paradigma da especialização flexível gerou novas possibilidades de organização e gestão produtiva das empresas, apresentando fortes ligações entre firmas locais, conexão com a infraestrutura ao redor e capacidade inovativa enxergada como um processo social.

\section{CONCLUSÕES}

O presente artigo teve como objetivo realizar uma revisão da literatura sobre os distritos industriais e sua contribuição para a discussão do desenvolvimento territorial. Essa discussão em torno das perspectivas de desenvolvimento para os diferentes territórios se constitui numa agenda de pesquisa que relaciona as interações entre as diferentes esferas, tais como, econômicas, sociais, culturais, políticas e ambientais.

Observou-se que as condições de reprodução e transformação do dinamismo dos distritos (seja de forma espontânea ou não) estão associadas à existência de sinergias internas atuantes, que vão desde recursos informacionais, capacitação e até de interação com os mercados externos. Por tal razão, as dimensões de regulação e governança ganham um papel fundamental para os desafios colocados em cada território.

A discussão perpassou pelo exemplo de sucesso da Terceira Itália e como tal região se tornou competitiva. Constatou-se uma confluência da análise para a valorização do papel dos atores sociais e das estratégias integradas de desenvolvimento local, o que reforça os esforços de uma inserção local para o global. 
Nesse sentido, a análise das diferentes compreensões sobre o desenvolvimento regional pode servir como norteadora para a implantação de políticas territoriais nos mais diversos espaços. Entretanto os aspectos relacionados aos territórios e ao modo de construção social, institucional e histórica inerentes a cada local, podem traçar resultados muito diferentes em outras localidades, devido às suas singularidades intrínsecas.

\section{REFERÊNCIAS}

ABREU, H. B. As novas configurações do Estado e da sociedade civil. In: Capacitação em Serviço Social e Política Social. Crise Contemporânea, Questão Social e Serviço Social. Brasília, DF: UnB, Centro de Educação Aberta, Continuada a Distância, 2000. Módulo 1, p. 35-44.

BAGNASCO, A. Desenvolvimento regional, sociedade local e economia difusa. In: COCCO, G.; URANI, A.; GALVÃO, A. P. (Org.). Empresários e empregos nos novos territórios produtivos: o caso da terceira Itália. Rio de Janeiro: DP\&A Editores, 1999.

BECATTINI, G. Os distritos industriais na Itália. In: COCCO, G.; URANI, A.; GALVÃO, A. P. (Org.). Empresários e empregos nos novos territórios produtivos: o caso da terceira Itália. Rio de Janeiro: DP\&A Editores, 1999.

BECATTINI, G. O Distrito Marshalliano. In: BENKO, G.; LIPIETZ, A. As regiões ganhadoras - distritos e redes: os novos paradigmas da geografia econômica. Tradução A. Gonçalves. Oeiras, Portugal: Celta, 1994.

BENKO, G.; LIPIETZ, A. (Org.). As regiões ganhadoras: distritos e redes: os novos paradigmas da geografia econômica. Oeiras, Portugal: Celt, 1994.

BENKO, G. Economia, espaço e globalização na aurora do século XXI. São Paulo: Hucitec, 2002.

BENKO, G. A recomposição dos espaços. Interações - Revista Internacional de Desenvolvimento Local, Campo Grande, MS, v. 1, n. 2, p. 7-12, mar. 2001.

BENKO, G. A ciência regional. Oeiras, Portugal: Celta, 1999.

BREITBACH, A. C. M. Estudo sobre o conceito de região. Porto Alegre, RS: Fundação de Economia e Estatística Siegfried Emanuel Heuser, 1988.

CLARK, C. The conditions of economic progress. London: Macmillan, 1957.

CHESNAIS, F. A mundialização do capital. São Paulo: Xamã, 1996.

CHRISTALLER, W. Central places in Southern Germany. New Jersey: Prentice-Hall, 1933.

DUAIBS, R. A economia italiana e o desenvolvimento dos distritos industriais. SINAIS, Vitória, ES, n. 20, p. 6-24, jul./dez. 2016.

ERBER, F. Eficiência coletiva em arranjos produtivos locais: comentando o conceito. Revista Nova Economia, Belo Horizonte, MG, v. 18, n. 1, p. 11-32, jan./abr. 2008.

FEITOSA, C. O. Aglomerações industriais como fator de desenvolvimento regional: um estudo de caso no Nordeste brasileiro. Malaga, Espanha: Eumed, 2009. v. 1, 63p.

HIRSCHMAN, A. O. Interregional and international transmission of economic growth. In: HIRSCHMAN, A. (Ed.). The strategy of economic development. New Haven: Hyatt Universit Press, 1958. p. 183-204. 
HUMPHREY, J.; SCHMITZ, H. The triple C approach to local industrial policy. World Development, v. 24, n. 12, p. 1859-77, dez. 1996.

LAURELL, A. C. Estado y políticas sociales en el neoliberalismo. México, DF: Fundación F. Ebert, 1992.

LOSCH, A. The economics of location. New Haven: Yale University Press, 1940.

MARSHALL, A. Princípios de economia. São Paulo: Nova Cultural, 1890. v. 1.

MYRDAL, G. Teoria econômica e regiões subdesenvolvidas. 2. ed. Rio de Janeiro: Saga, 1968.

MARTINS, C. E. Da globalização da economia à falência da democracia. Economia e Sociedade; Campinas, SP, v. 5, n. 1, p. 1-23, jun. 1996.

OTTAVIANO, G. I. P.; THISSE J. F. New economic geography: what about the N? Environment and Planning A, v. 37, n. 10, p. 1707-25, 2004.

PIORE, M. J.; SABEL C. The second industrial divide. New York: Basic Books, 1984.

PORTER, M. Competição: estratégias competitivas essenciais. Rio de Janeiro: Elsevier/ Campus, 1999.

ROSTOW, W. W. Etapas do desenvolvimento econômico: (um manifesto não comunista). 2. ed. Rio de Janeiro: Zahar, 1978.

SCHMITZ, H. On the clustering of small firms. IDS Bulletin, v. 23, n. 3, p. 64-6, jul. 1992.

SCHMITZ, H.; MUSYCK, B. Industrial districts in Europe: policy lessons for developing countries? University of Sussex, Institute of Developing Studies, Discussion Paper 324, abr. 1993.

SCHMITZ, H.; NADVI, K. Clustering and industrialization: introduction. World Development, v. 27, n. 9, p. 1503-14, 1999.

VERNON, R. International investment and international trade in the product cycle. The Quarterly Journal of Economics, v. 80, n. 2, p. 190-207, maio 1966.

\section{Sobre os autores:}

Elaine Carvalho de Lima: Estudante do doutorado em Economia pela Universidade Federal de Uberlândia (UFU). Possui mestrado em Economia pela Universidade Federal do Rio Grande do Norte (UFRN). Especialista em Educação Ambiental e Geografia do Semiárido pelo Instituto Federal do Rio Grande do Norte (IFRN). Especialista em Gestão Pública Municipal pela Universidade Estadual da Paraíba (UFPB). E-mail: elainecarvalhoonline@hotmail.com

Calisto Rocha de Oliveira Neto: Professor da Universidade Federal Rural do Semiárido (UFERSA). Mestre e graduado em Economia pela Universidade Federal do Rio Grande do Norte (UFRN). Graduando em Ciências Contábeis pela UFRN. E-mail: calisto_neto@hotmail.com 
